Check for updates

Cite this: RSC Adv., 2017, 7, 46594

Received 17th July 2017

Accepted 27th September 2017

DOI: $10.1039 / c 7 r a 07870 f$

rsc.li/rsc-advances

\section{Significantly improved cyclability of lithium manganese oxide, simultaneously inhibiting electrochemical and thermal decomposition of the electrolyte by the use of an additive $\uparrow$}

\begin{abstract}
Bo Liao, ${ }^{a}$ Hongying Li, ${ }^{a}$ Xianshu Wang, ${ }^{a}$ Mengqing $\mathrm{Xu}^{\mathrm{ab}}$ Lidan Xing, ${ }^{\text {ab }}$ Youhao Liao, ${ }^{\mathrm{ab}}$ Xiang Liu*ab and Weishan Li (ID *ab

Lithium manganese oxide $\left(\mathrm{LiMn}_{2} \mathrm{O}_{4}\right)$ is one of the most promising cathodes for lithium ion batteries because of its abundant resources and easy preparation. However, its poor cyclability, especially under elevated temperature, limits its application on a large scale. In this work, it is reported that the cyclability of $\mathrm{LiMn}_{2} \mathrm{O}_{4}$ can be significantly improved by applying 4-(trifluoromethyl)benzonitrile (4-TB) as an electrolyte additive. Charge/discharge tests indicate that the capacity retention of $\mathrm{LiMn}_{2} \mathrm{O}_{4}$ after 450 cycles at $1 \mathrm{C}$ and $55{ }^{\circ} \mathrm{C}$ in a standard electrolyte, $1 \mathrm{M} \mathrm{LiPF}_{6}$ in EC/EMC/DEC (3:5:2, in weight), is improved from $19 \%$ to $69 \%$. Further electrochemical and physical characterization demonstrates that 4TB can, on the one hand, be electrochemically oxidized preferentially compared to the standard electrolyte, which generates a protective interphase film on $\mathrm{LiMn}_{2} \mathrm{O}_{4}$. On the other hand, 4-TB can effectively combine with protonic impurities, which inhibits the thermal decomposition of the electrolyte. This dual-functionality of 4-TB contributes to the significantly improved cyclability of $\mathrm{LiMn}_{2} \mathrm{O}_{4}$.
\end{abstract}

\section{Introduction}

Lithium ion batteries are the most used power sources for electric vehicles due to their high energy density and environmental friendliness compared with other secondary batteries. ${ }^{1-3}$ Cobalt-containing oxides such as $\mathrm{LiCoO}_{2}$ and ferrous phosphates such as $\mathrm{LiFePO}_{4}$ are the mainstream cathodes of commercial lithium ion batteries. However, cobalt is rare on earth and the preparation of ferrous phosphates is complicated, leading to the high cost of currently commercialized lithium ion batteries. To apply lithium ion batteries more widely, it is necessary to reduce the cost of manufacturing lithium ion batteries. Spinel $\mathrm{LiMn}_{2} \mathrm{O}_{4}$ is one of the most promising cathodes for lowering the cost of lithium ion batteries, owing to the abundance of manganese and the easy preparation of $\mathrm{LiMn}_{2} \mathrm{O}_{4} \cdot{ }^{4,5}$ However, the poor cyclability of $\mathrm{LiMn}_{2} \mathrm{O}_{4}$, especially under elevated temperature, limits its application in practice, ${ }^{6-8}$ which is caused by the poor compatibility of $\mathrm{LiMn}_{2} \mathrm{O}_{4}$ with carbonate-based electrolytes. ${ }^{9,10}$

${ }^{a}$ School of Chemistry and Environment, South China Normal University, Guangzhou 510006, China.E-mail: iamxliu@njtech.edu.cn; liwsh@scnu.edu.cn

${ }^{b}$ Engineering Research Center of MTEES (Ministry of Education), Research Center of BMET (Guangdong Province), Engineering Lab. of OFMHEB (Guangdong Province), Key Lab. of ETESPG, GHEI, Innovative Platform for ITBMD (Guangzhou Municipality), South China Normal University, Guangzhou 510006, China

$\dagger$ Electronic supplementary information (ESI) available. See DOI: 10.1039/c7ra07870f
The carbonate-based electrolytes might be decomposed electrochemical-oxidatively on charged cathode or thermally under elevated temperature. ${ }^{11,12}$ The electrochemical-oxidation decomposition of electrolyte takes place in the form of complexes of solvents with anion $\mathrm{PF}_{6}{ }^{-}$, yielding $\mathrm{HF}^{.13}$ On the other hand, the electrolyte also suffers thermal decomposition when it is stored under elevated temperature. $\mathrm{HF}$ is also generated during the thermal decomposition due to the reactions of $\mathrm{LiPF}_{6}$ with trace protonic impurities in the electrolyte such as $\mathrm{H}_{2} \mathrm{O} .{ }^{14,15}$ The resulting $\mathrm{HF}$ from the electrochemicaloxidative or thermal decompositions causes manganese dissolution of $\mathrm{LiMn}_{2} \mathrm{O}_{4}$ or even the corrosion of aluminum (current collector), leading to the poor cyclability of $\mathrm{LiMn}_{2} \mathrm{O}_{4}$.

Several methods have been reported to mitigate the electrochemical-oxidation decomposition of the electrolyte, including partially substituting transition metal elements such as $\mathrm{Co}$ and $\mathrm{Ni}$ for $\mathrm{Mn}$ or non-metal elements such as $\mathrm{F}$ for $\mathrm{O}$ in $\mathrm{LiMn}_{2} \mathrm{O}_{4}{ }^{16,17}$ coating $\mathrm{LiMn}_{2} \mathrm{O}_{4}$ with inert materials, ${ }^{18,19}$ designing $\mathrm{LiMn}_{2} \mathrm{O}_{4}$ with special crystal plane, ${ }^{20}$ and using electrolyte additives that can help build protective interphase film on $\mathrm{LiMn}_{2} \mathrm{O}_{4} \cdot{ }^{21-23}$ Comparatively, less attention has been paid to the inhibition of the thermal decomposition of the electrolyte.

Previously, we developed a new additive, 4-(trifluoromethyl) benzonitrile (4-TB), to enhance the cyclability of $\mathrm{LiNi}_{0.5} \mathrm{Mn}_{1.5} \mathrm{O}_{4}$ under $4.9 \mathrm{~V}$ (ref. 24) and $\mathrm{LiCoO}_{2}$ under $4.5 \mathrm{~V}$ (ref. 25). It was found that 4-TB could combine transition metal ions in cathode and then be oxidized preferentially compared to the solvents. 
This preference helps build a protective interphase film that can suppress the electrochemical-oxidation decomposition of the electrolyte. In this work, we report that 4-TB can not only be electrochemical-oxidized preferentially, which helps build a protective interphase film on $\mathrm{LiMn}_{2} \mathrm{O}_{4}$, but also coordinates protonic impurities in electrolyte, which mitigates the thermal stability of the electrolyte. This dual-functionality of electrolyte additive has not been reported before in literature and provides a new approach for improving the cyclability of cathodes of lithium ion batteries, not limited to $\mathrm{LiMn}_{2} \mathrm{O}_{4}$.

\section{Experimental and calculation}

\section{Sample preparation}

4-(Trifluoromethyl)benzonitrile (4-TB, >99\%) was purchased from Alfa Aesar Technology Co., Ltd. A standard (STD) electrolyte with water content controlled to less than $10 \mathrm{ppm}$, $1 \mathrm{~mol} \mathrm{~L}^{-1}$ lithium hexafluorophosphate $\left(\mathrm{LiPF}_{6}\right)$ in a mixed solvent of ethylene carbonate (EC)/ethyl methyl carbonate (EMC)/diethyl carbonate (DEC) (3:5:2, in weight) was provided by Guangzhou Tinci Materials Technology Co., Ltd., China. These chemicals were used without further purification. The electrolyte containing 4-TB was prepared in an argon-filled glove box (MBraun, Germany), by adding 4-TB into the STD electrolyte. $0.5 \mathrm{wt} \%$ 4-TB, which was found to be the optimal content for the cyclability improvement of $\mathrm{LiNi}_{0.5} \mathrm{Mn}_{1.5} \mathrm{O}_{4}$ under $4.9 \mathrm{~V}$ (ref. 24) and $\mathrm{LiCoO}_{2}$ under $4.5 \mathrm{~V}$ (ref. 25) in our previous reports, was considered in this work.

$\mathrm{LiMn}_{2} \mathrm{O}_{4}$ working electrode consists of $80 \mathrm{wt} \% \mathrm{LiMn}_{2} \mathrm{O}_{4}$ (Hunan Dahua New Energy Co., Ltd., China), 10 wt\% conductive carbon (TIMCAL Ltd., Switzerland), and $10 \mathrm{wt} \%$ PVDF (Ofluorine Chemical Tech Co., Ltd., China). The mixture was coated on aluminum current corrector, dried at $120{ }^{\circ} \mathrm{C}$ for $8 \mathrm{~h}$, and punched into disks of $1.13 \mathrm{~cm}^{2}$. To ensure the consistency of all the electrodes, the loading of $\mathrm{LiMn}_{2} \mathrm{O}_{4}$ in the electrodes were controlled at the level of $1.93 \pm 0.01 \mathrm{mg} \mathrm{cm}^{-2}$. Coin cells (2025type) were assembled with lithium foil as counter electrode and microporous membrane (Celgard 2400) as separator in the glove box mentioned above.

\section{Electrochemical measurements}

Charge/discharge performances of $\mathrm{Li} / \mathrm{LiMn}_{2} \mathrm{O}_{4}$ cells were tested on a LAND system (CT2001A, Wuhan, China) under $25{ }^{\circ} \mathrm{C}$ and $55{ }^{\circ} \mathrm{C}$ at $0.5 \mathrm{C}\left(1 \mathrm{C}=148 \mathrm{~mA} \mathrm{~h} \mathrm{~g}{ }^{-1}\right)$ rate for the initial three formation cycles and at $1 \mathrm{C}$ rate for the remaining cycles between 3.0 and $4.5 \mathrm{~V}$. Chronoamperometry and electrochemical impedance spectroscopy (EIS) were performed on Autolab (Metrohm, Netherlands) at room temperature. In chronoamperometry, $\mathrm{Li} / \mathrm{LiMn}_{2} \mathrm{O}_{4}$ cells were charged to $4.5 \mathrm{~V}$ at $0.1 \mathrm{C}$ and then kept at this voltage for $13.5 \mathrm{~h}$. EIS was carried out at discharged state with a sinusoidal modulation of $5 \mathrm{mV}$ from $100 \mathrm{kHz}$ to $0.01 \mathrm{~Hz}$. To ensure the accuracy of the experimental results, all the electrochemical measurements were performed with five cells for every sample and the reported results in this work were taken from the cells that represented the mean values of five cells.

\section{Chemical analysis and physical characterization}

The thermal stability of electrolyte was evaluated by storing the electrolyte under elevated temperature. The electrolyte was injected to polytetrafluoroethylene (PTFE) bottle, which was packed in aluminum-plastic bag and stored in vacuum oven at $55^{\circ} \mathrm{C}$ for $72 \mathrm{~h}$. The hydrofluoric acid (HF) content in electrolytes was analyzed by $\mathrm{NaOH}$ titration with bromothymol blue as indicator.

GC-MS was performed using Agilent 7890A and 7895C (Agilent Technologies Inc., America) for analyzing the change in electrolyte composition after storage under elevated temperature and confirming the interaction of additive with protonic impurities. Morphology of $\mathrm{LiMn}_{2} \mathrm{O}_{4}$ electrodes was observed with SEM (ZEISS ULTRA 55, Germany) and TEM (JEM-2100, JOEL, Japan). Surface composition on $\mathrm{LiMn}_{2} \mathrm{O}_{4}$ electrodes was determined by XPS (Thermo Scientific, K-Alpha, US). The contents of manganese and aluminum on lithium electrodes of the cycled cell were determined by ICP-AES (Optima 8300, US). Crystal structure of $\mathrm{LiMn}_{2} \mathrm{O}_{4}$ electrodes was analyzed by XRD (Bruker D8 Advance, Germany). The electrodes taken from the cycled cells were cleaned with DMC to remove the residual electrolyte and dried before physical characterizations.

\section{Theoretical calculation}

The highest occupied molecular orbital (HOMO) energy of EC, EMC, DEC and 4-TB was calculated with Gaussian 09 software package. The equilibrium state structures were optimized by B3LYP method at 6-311++G (d) basis set.

\section{Results and discussion}

\section{Cycle performances of $\operatorname{LiMn}_{2} \mathrm{O}_{4}$ under elevated temperature}

Fig. 1 presents the cycle performance of $\operatorname{LiMn}_{2} \mathrm{O}_{4}$ electrode in the electrolytes with and without $0.5 \mathrm{wt} \% 4$-TB at $1 \mathrm{C}$ under $55^{\circ} \mathrm{C}$. As shown in Fig. 1a, which presents the representative one of five samples for each electrode (Fig. $\mathrm{S} 1 \dagger$ ), $\mathrm{LiMn}_{2} \mathrm{O}_{4}$ exhibits poor cyclability after cycling in the STD electrolyte: retaining a discharge capacity of only $21 \mathrm{~mA} \mathrm{~h} \mathrm{~g}^{-1}$ and providing a capacity retention of only $19 \%$. Correspondingly, its coulombic efficiency is low (Fig. 1b) and its discharge profile after deep cycling becomes different completely from its initial one (Fig. 1c). This is the main issue that restricts the utilization of $\mathrm{LiMn}_{2} \mathrm{O}_{4}$ in practice. The electrochemical-oxidative and thermal decompositions are responsible for this poor cyclability. The electrolyte might be decomposed electrochemically on $\mathrm{LiMn}_{2} \mathrm{O}_{4}$ during charge process and thermally under elevated temperature. Both of these decompositions yield $\mathrm{HF}$ that causes the manganese dissolution from $\mathrm{LiMn}_{2} \mathrm{O}_{4}$, leading to the final structural collapse. The continuous discharge capacity decaying up to the $280^{\text {th }}$ cycle for the $\mathrm{LiMn}_{2} \mathrm{O}_{4}$ cycled in the STD electrolyte can be attributed to the increased polarization resulting from the electrolyte decomposition products ${ }^{26}$ while the abrupt discharge capacity decay from the $280^{\text {th }}$ cycle can be ascribed to the structural collapse $\mathrm{LiMn}_{2} \mathrm{O}_{4} \cdot{ }^{27}$

When 4-TB is employed, the cyclability of $\mathrm{LiMn}_{2} \mathrm{O}_{4}$ is improved significantly, as shown in Fig. 1a. The capacity retention is enhanced to $69 \%$. Compared to the $\mathrm{LiMn}_{2} \mathrm{O}_{4}$ cycled in the electrolyte without additive, the $\mathrm{LiMn}_{2} \mathrm{O}_{4}$ cycled in the additive- 

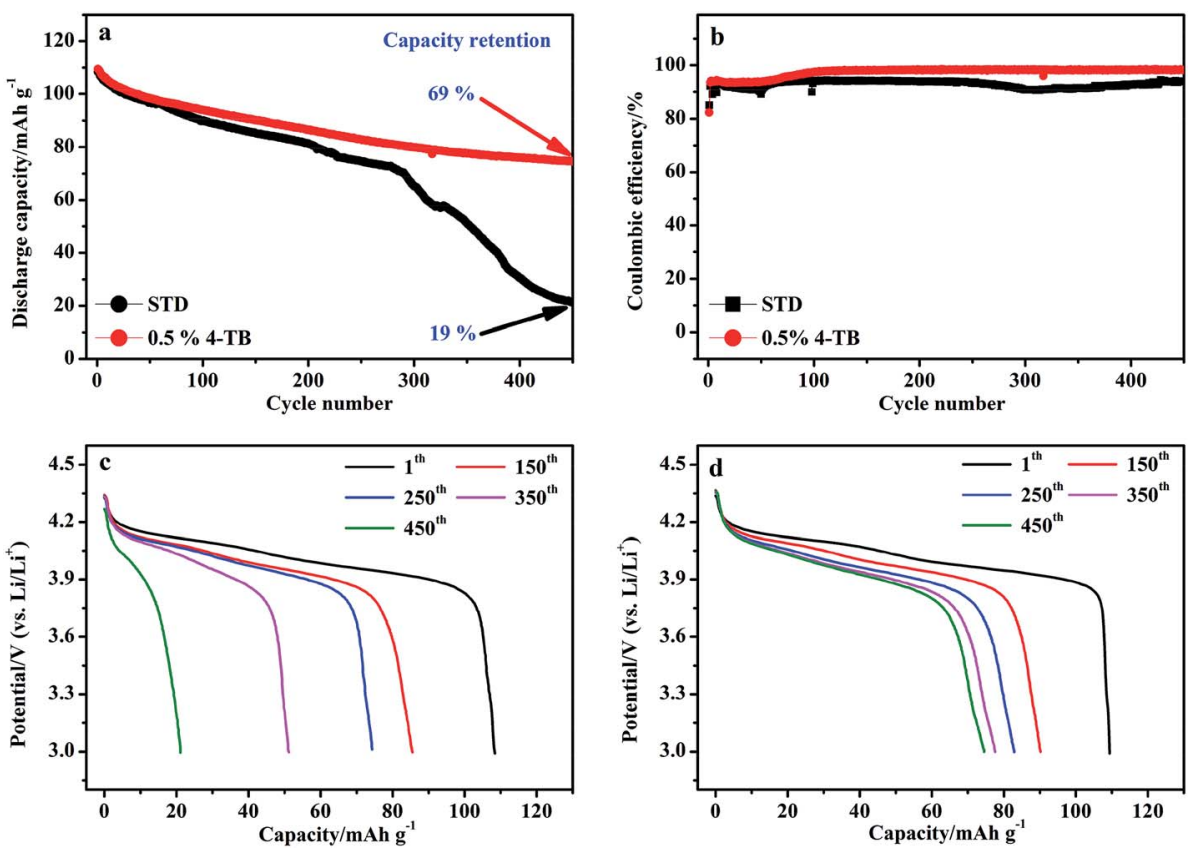

Fig. 1 Cyclability (a), coulombic efficiency (b), and discharge curves at selected cycles in STD (c) and 4-TB-containing (d) electrolytes for $\mathrm{LiMn}_{2} \mathrm{O}_{4}$ electrodes at $1 \mathrm{C}$ under $55^{\circ} \mathrm{C}$. The electrodes were performed with three cycles at $0.5 \mathrm{C}$ under room temperature before cycling.

containing electrolyte shows less capacity decay before the $280^{\text {th }}$ cycle. Most importantly, no abrupt discharge capacity decay is observed for the $\mathrm{LiMn}_{2} \mathrm{O}_{4}$ cycled in the additive-containing electrolyte. Correspondingly, the coulombic efficiency of $\mathrm{LiMn}_{2} \mathrm{O}_{4}$ cycled in the additive-containing electrolyte remains higher (Fig. 1b) and its discharge profile after deep cycling changes insignificant (Fig. 1d). It is apparent that 4-TB can inhibit the decomposition of electrolyte and the structural collapse of $\mathrm{LiMn}_{2} \mathrm{O}_{4}$.

Various electrolyte additives have been proposed for the cyclability improvement of $\mathrm{LiMn}_{2} \mathrm{O}_{4}$, which are usually based on the interphase film generated from the additives. ${ }^{21-23}$ Compared with these additives, 4-TB behaves better for the cyclability improvement of $\mathrm{LiMn}_{2} \mathrm{O}_{4}$. For example, applying $3 \mathrm{wt} \%$ tripropyl borate yields a capacity retention of only $74 \%$ for $\mathrm{LiMn}_{2} \mathrm{O}_{4}$ after 200 cycles at $1 \mathrm{C}$ under $55{ }^{\circ} \mathrm{C} .{ }^{27}$ Comparatively, the capacity retention is $80 \%$ by using only $0.5 \mathrm{wt} \% 4$-TB for the $\mathrm{LiMn}_{2} \mathrm{O}_{4}$ cycled under the same rate, same temperature and same cycle number. Since the capacity decay of $\operatorname{LiMn}_{2} \mathrm{O}_{4}$ under elevated temperature is related to not only the electrochemical-oxidation decomposition but also the thermal decomposition of the electrolyte, the improved cyclability of $\mathrm{LiMn}_{2} \mathrm{O}_{4}$ is also attributed to the thermal stability improvement of electrolyte by 4 -TB besides of its contribution to the inhibition of the electrochemical-oxidation decomposition of the electrolyte. To confirm these contributions, the interphase film formed from 4-TB and the interaction between 4-TB and electrolyte were identified separately.

\section{Interphase film formed from 4-TB}

As an effective additive for forming an interphase film that can suppress electrolyte decomposition, it should be oxidized electrochemically on the cathode surface before STD electrolyte. The preferential electrochemical-oxidation of 4-TB can be indicated by its higher highest occupied molecular orbit (HOMO) energy than those of solvents, as shown in Fig. 2a. To further confirm the preferential electrochemical-oxidation of 4$\mathrm{TB}$, the initial charge/discharge process of $\mathrm{LiMn}_{2} \mathrm{O}_{4}$ was analyzed further. Fig. $2 \mathrm{~b}$ presents the differential capacity $(\mathrm{d} Q /$ $\mathrm{d} V$ ) curve of $\mathrm{LiMn}_{2} \mathrm{O}_{4}$ in electrolytes with and without 4-TB during the initial cycle of Fig. 1a. Both electrodes show two apparent redox peaks, which are characteristic of spinel $\mathrm{LiMn}_{2} \mathrm{O}_{4}$ for typical lithium insertion/extraction. ${ }^{6}$ Compared with the electrode in the STD electrolyte, the $\mathrm{LiMn}_{2} \mathrm{O}_{4}$ in the 4TB-containing electrolyte shows an additional small oxidation peak before lithium extraction, as shown in Fig. 2b, suggesting that 4-TB can be oxidized on $\mathrm{LiMn}_{2} \mathrm{O}_{4}$ during charge process. This oxidation peak potential is about $3.85 \mathrm{~V}$, suggesting that 4$\mathrm{TB}$ is far more easily oxidized during charge process than the solvents in the STD electrolyte, which is usually stable at the potential lower than $4.2 \mathrm{~V}$. The preferential electrochemicaloxidation of 4-TB might help build a protective interphase film that inhibits the electrolyte electrochemical-oxidation decomposition and the structural collapse of $\mathrm{LiMn}_{2} \mathrm{O}_{4}$.

Fig. 2c presents the choronoamperometric responses of $\mathrm{LiMn}_{2} \mathrm{O}_{4}$ electrodes, which were charged to $4.5 \mathrm{~V}$ at $0.1 \mathrm{C}$ and then kept at this voltage in the electrolytes with and without 4TB. As shown in Fig. 2c, the electrode in the STD electrolyte has a large residue current during constant voltage process. Since the electrode is charged at a low rate current and the lithium ions in $\mathrm{LiMn}_{2} \mathrm{O}_{4}$ should be extracted completely, the residue current should be attributed to the serious decomposition of the electrolyte. Differently, the $\mathrm{LiMn}_{2} \mathrm{O}_{4}$ electrode in the 

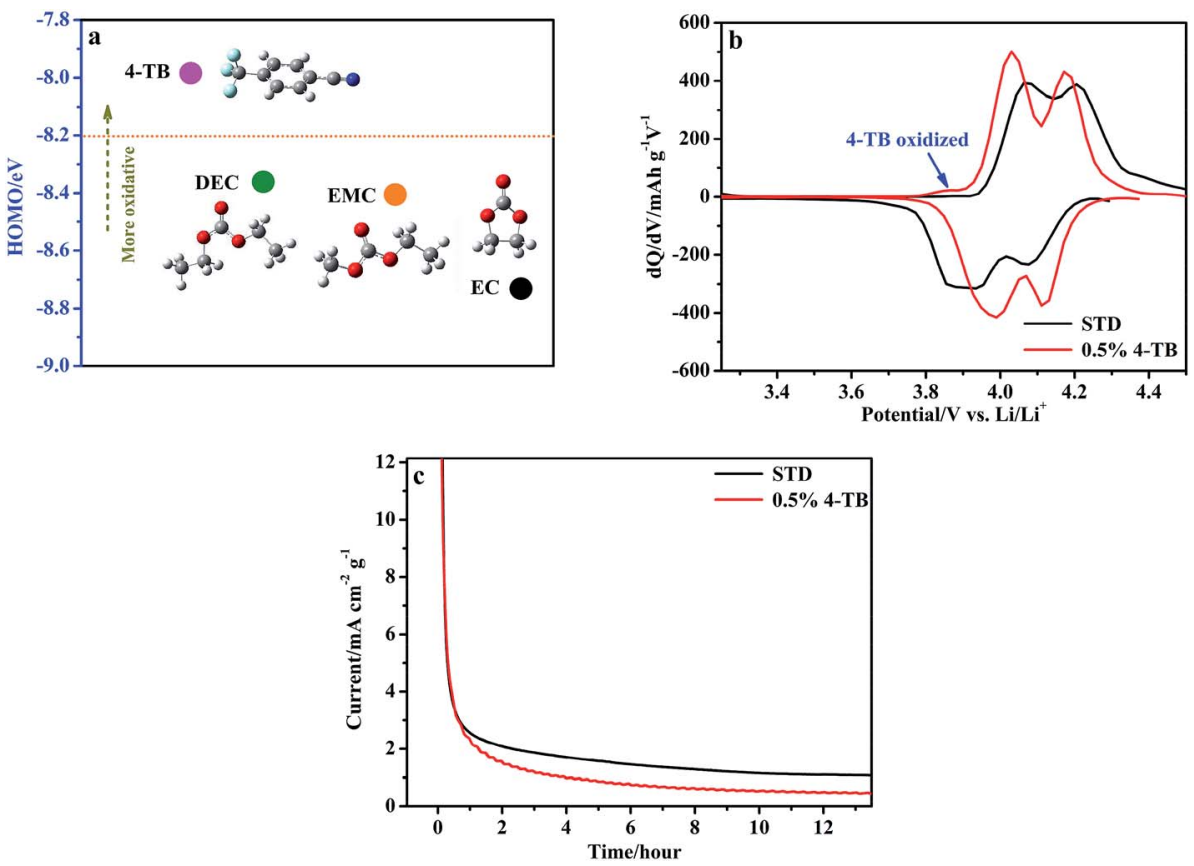

Fig. 2 Calculated HOMO energy (eV) levels of 4-TB, EC, EMC and DEC (a) initial differential charge/discharge capacity curves at 0.5C (b) and chronoamperograms (c) at $4.5 \mathrm{~V}$ after charging at $0.1 \mathrm{C}$ for $\mathrm{LiMn}_{2} \mathrm{O}_{4}$ electrodes in STD and 4-TB-containing electrolytes.

additive-containing electrolyte has a far smaller residue current, suggesting that the interphase film resulting from the preferential electrochemical-oxidation of 4-TB can effectively inhibit the electrolyte electrochemical-oxidation decomposition.

It can be noted from the peak positions of Fig. $2 \mathrm{~b}$ that the electrode in the electrolyte without additive is more polarized for lithium insertion/extraction than that in the additivecontaining electrolyte. This difference suggests that the interphase film formed from 4-TB is beneficial for the lithium insertion/extraction, which can be indicated by the smaller interfacial impedance of the electrode cycled in the additivecontaining electrolyte. Fig. 3 presents the electrochemical impedance spectra of $\mathrm{LiMn}_{2} \mathrm{O}_{4}$ electrodes in the electrolytes with and without 4 -TB after 1 and 10, 450 cycles. The impedance spectra show a linear relation at low frequencies, associated with Li-ion diffusion, and one or more semicircles at high frequencies, representing interfacial properties including charge transfer and interphase film impedance. ${ }^{27,28}$ It can be found, by comparing the semicircles at high frequencies between two electrodes cycled initially (at the first and $10^{\text {th }}$ cycles), that the electrode cycled in the additive-containing electrolyte has smaller interfacial impedance than that in the STD electrolyte, indicative of the less polarization for lithium insertion/extraction on $\mathrm{LiMn}_{2} \mathrm{O}_{4}$ with the interphase film formed by 4-TB. The interfacial impedance of the cells with STD electrolyte (Fig. 3a) increases significantly after cycling, showing the interfacial instability of electrode/electrolyte. This instability results from the products of electrolyte decomposition on $\mathrm{LiMn}_{2} \mathrm{O}_{4}$ and the manganese dissolution that causes the structural collapse of $\mathrm{LiMn}_{2} \mathrm{O}_{4}$. Differently, the impedance spectra of the cells with 4-TB show less change from initial cycle to the last cycle, as shown in Fig. 3b. Obviously, the application of 4-TB can maintain the interfacial stability of $\mathrm{LiMn}_{2} \mathrm{O}_{4} /$ electrolyte during cycling under elevated temperature. The interphase film originated from the preferential electrochemical-
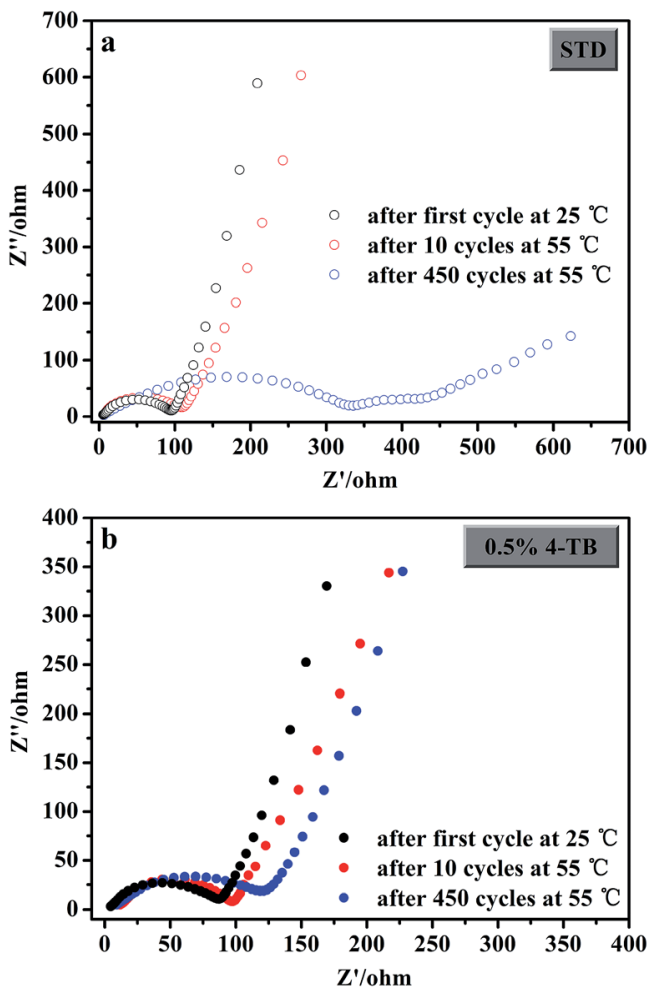

Fig. 3 Electrochemical impedance spectra of $\mathrm{LiMn}_{2} \mathrm{O}_{4}$ electrodes in the STD (a) and 4-TB-containing (b) electrolytes after cycling. 

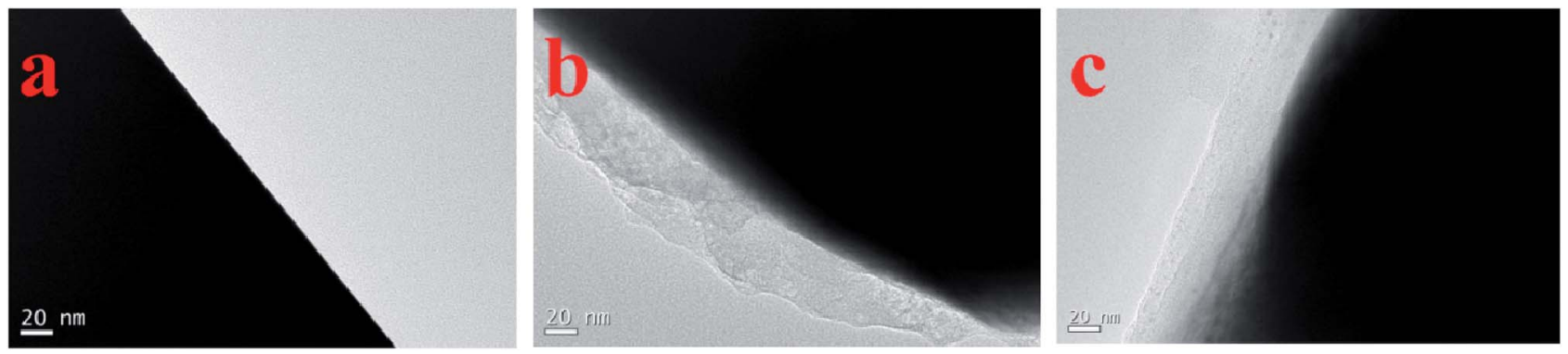

Fig. 4 TEM images of fresh $\mathrm{LiMn}_{2} \mathrm{O}_{4}$ electrode (a) and the cycled ones in STD (b) and 4-TB-containing (c) electrolytes.

oxidation of 4-TB not only suppresses the electrolyte electrochemical-decomposition but also prevents $\mathrm{LiMn}_{2} \mathrm{O}_{4}$ from structural collapse. The interphase film formed from 4-TB can be confirmed by TEM. Fig. 4 presents the TEM images of the $\mathrm{LiMn}_{2} \mathrm{O}_{4}$ particles from the cycled electrodes in the electrolytes with and without additive, with a comparison of fresh one.
Smooth and clean surface can be observed on the fresh particle (Fig. 4a). After cycling in the electrolyte without additive, the particle is covered with thick and inhomogeneous deposit (Fig. 4b), indicative of the electrolyte decomposition during cycling. In the electrolyte with additive, however, a thin and
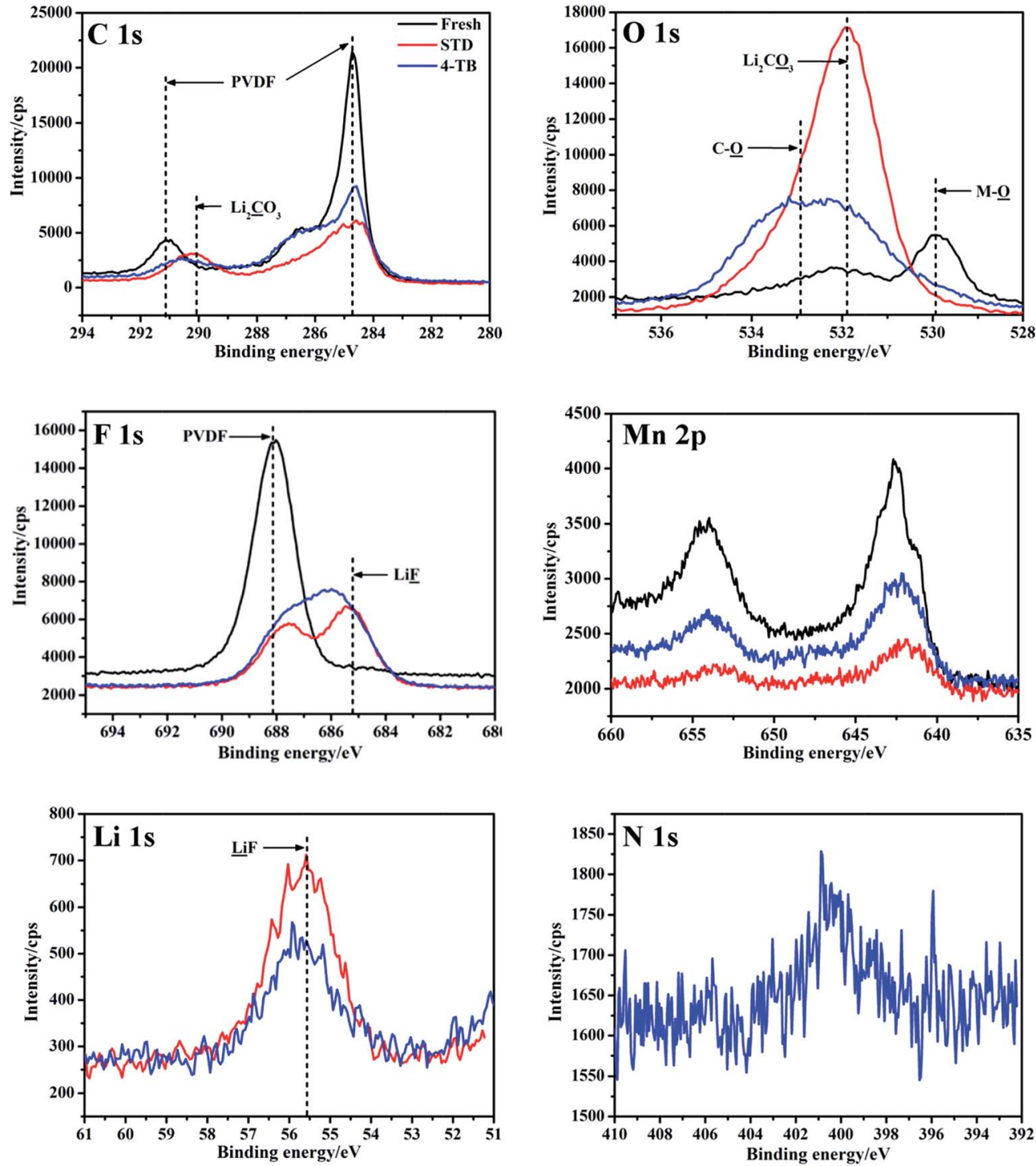

Fig. 5 XPS profiles of the cycled $\mathrm{LiMn}_{2} \mathrm{O}_{4}$ electrodes in STD and 4-TB-containing electrolytes at $55^{\circ} \mathrm{C}$, with a comparison of the fresh one. 
uniform interphase film can be identified on the particle, as shown in Fig. 4c.

Fig. 5 presents XPS profiles of the $\mathrm{LiMn}_{2} \mathrm{O}_{4}$ electrodes in the electrolytes with and without 4-TB after 450 cycles at $1 \mathrm{C}$ under $55{ }^{\circ} \mathrm{C}$, with a comparison of the fresh one. The cycled electrodes show their XPS profiles differently from the fresh one. The main compositions of the electrode including PVDF as binder, Mn and $\mathrm{O}$ in $\mathrm{LiMn}_{2} \mathrm{O}_{4}$, can be obviously identified on the fresh electrode: the significant peaks at 285 and $291 \mathrm{eV}$ in C $1 \mathrm{~s}$ and at $688 \mathrm{eV}$ in $\mathrm{F}$ 1s correspond to PVDF; while those at $530 \mathrm{eV}$ in $\mathrm{O} 1 \mathrm{~s}$ and at 643 and $653 \mathrm{eV}$ in $\mathrm{Mn} 2 \mathrm{p}$ correspond to metal-oxide bonds. ${ }^{29,30}$ After cycling, however, the intensities of these peaks are reduced in the STD and additive-containing electrolytes, suggesting that the cycled electrodes have been covered by the electrolyte decomposition products. Comparatively, the reduced magnitude of these peaks is more significant for the electrode cycled in the electrolyte without additive than that cycled in the electrolyte with additive, suggesting that there are more electrolyte decomposition products existing on the electrode cycled in the STD electrolyte. Obviously, electrolyte decomposes continuously on the $\mathrm{LiMn}_{2} \mathrm{O}_{4}$ electrode in the electrolyte without additive during cycling process, resulting in the accumulation of the electrolyte decomposition products. In the electrolyte with additive, however, an interphase film is generated from the preferential electrochemical-oxidation of 4TB and the electrolyte electrochemical-oxidation decomposition is inhibited, resulting in the stronger peak intensities of PVDF and metal-oxide bonds compared with those in the electrolyte without additive.

In fact, the peaks at $290 \mathrm{eV}$ in $\mathrm{C} 1 \mathrm{~s}$ and at $532 \mathrm{eV}$ in $\mathrm{O} 1 \mathrm{~s}$, both of which correspond to $\mathrm{Li}_{2} \mathrm{CO}_{3}$, and the peak at $56 \mathrm{eV}$ in $\mathrm{Li} 1 \mathrm{~s}$, which corresponds to $\mathrm{LiF},{ }^{31}$ can be observed more clearly for the electrode cycled in the electrolyte without additive than that in the electrolyte with additive. Since $\mathrm{Li}_{2} \mathrm{CO}_{3}$ and $\mathrm{LiF}$ are the main products of electrolyte decomposition, ${ }^{32}$ the weaker peaks for $\mathrm{Li}_{2} \mathrm{CO}_{3}$ and $\mathrm{LiF}$ on the electrode cycled in 4-TB-containing $\mathbf{a}$
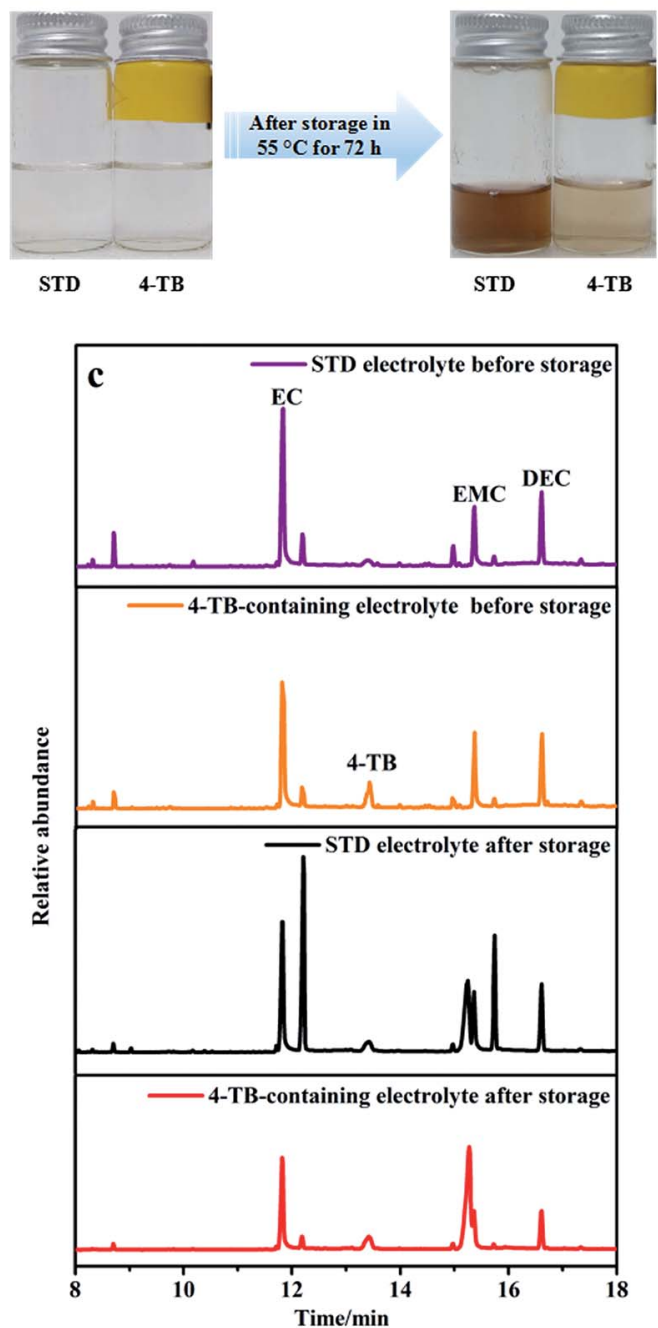
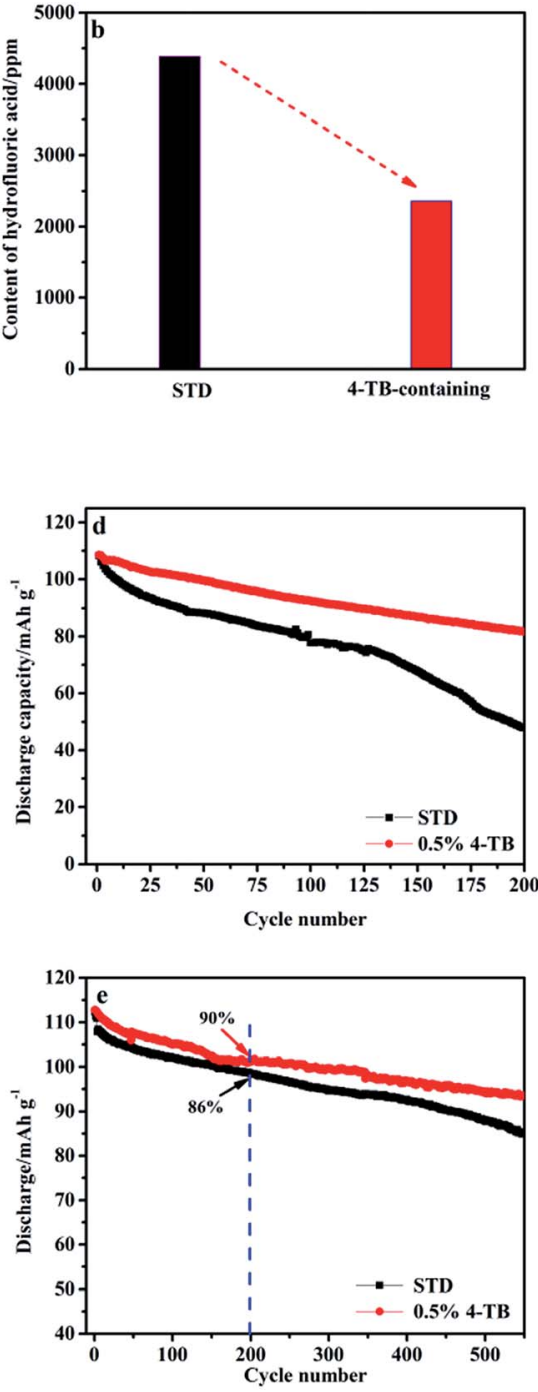

Fig. 6 Changes in color (a), HF content (b) and GC-MS spectrum (c) of the electrolytes after storage at $55^{\circ} \mathrm{C}$ for $72 \mathrm{~h}$. Cyclability of LiMn $\mathrm{O}_{4}$ electrodes at $0.5 \mathrm{C}$ for the first three cycles and at $1 \mathrm{C}$ for the subsequent cycles under $25^{\circ} \mathrm{C}$, using the electrolytes after (d) and before (e) storage. 
electrolyte confirm that the electrolyte decomposition can be inhibited by applying 4-TB. It should be noted that an unidentified peak near LiF in $\mathrm{F}$ 1s spectrum appears for the electrode cycled in the electrolyte with additive, suggesting that $\mathrm{F}$ in 4-TB has been incorporated into the interphase film. The element $\mathrm{N}$ existing in 4-TB can only be detected in $\mathrm{N} 1 \mathrm{~s}$ for the electrode cycled in the electrolyte with additive, confirming that the products from the preferential electrochemical-oxidation of 4TB has been incorporated into the protective interphase film that inhibits the electrolyte electrochemical-oxidation decomposition and prevents $\mathrm{LiMn}_{2} \mathrm{O}_{4}$ from structural collapse.

\section{Improved thermal stability of electrolyte by 4-TB}

To confirm the effect of 4-TB on the thermal stability of electrolyte, the STD and $0.5 \mathrm{wt} \%$ 4-TB-containing electrolytes were stored at $55{ }^{\circ} \mathrm{C}$ for $72 \mathrm{~h}$. The photos of the electrolytes before and after storage tests are shown in Fig. 6a. It can be seen from Fig. 6a that the color of the STD electrolyte turns to far brown than that of the electrolyte containing 4-TB, confirming that the electrolyte without additive suffers serious thermal decomposition that can be inhibited to a great extent by applying 4-TB. The composition change of the electrolytes after storage was monitored by acid-base titration and GC-MS analysis, and the effect of the electrolytes after storage on the cyclability of $\mathrm{LiMn}_{2} \mathrm{O}_{4}$ was evaluated in coin cell under room temperature. Fig. $6 \mathrm{~b}$ presents the increased HF concentrations of the electrolytes after storage. Correspondingly to the color change observed in Fig. 6a, there is a significantly increased concentration of $\mathrm{HF}$ (4386 ppm) in the STD electrolyte after storage, about two times that in the 4-TB-containing electrolyte after storage (2356 ppm). $\mathrm{HF}$ will erode $\mathrm{LiMn}_{2} \mathrm{O}_{4}$, leading to the capacity decay of $\mathrm{LiMn}_{2} \mathrm{O}_{4}$.

Fig. 6c presents the GC-MS spectra of the electrolytes with and without 4 -TB before and after storage at $55{ }^{\circ} \mathrm{C}$ for $72 \mathrm{~h}$. Both electrolytes have similar spectra: three main peaks at 11.8, 15.3 and $16.6 \mathrm{~min}$, representing EC, EMC and DEC, respectively, and other minor peaks at 8.7, 12.2, 13.4, 14.9 and $15.7 \mathrm{~min}$, which should be ascribed to the coordination of solvents with ions in $\mathrm{LiPF}_{6}$ or trace impurities in the electrolyte. Differently, the additional peak at $13.4 \mathrm{~min}$ is stronger in the electrolyte containing 4-TB. This peak might come from the contribution of 4TB, which can be confirmed later. In the STD electrolyte after storage, the peaks representing EC and EMC become weaker, while the peaks at 12.2, 14.9 and $15.7 \mathrm{~min}$ become stronger, indicating that the STD electrolyte is unstable thermally. Under elevated temperature, $\mathrm{LiPF}_{6}$ will decompose into $\mathrm{PF}_{5}$, which reacts rapidly with protonic impurities such as $\mathrm{ROH}$ or $\mathrm{H}_{2} \mathrm{O}$ forming $\mathrm{HF}$ and $\mathrm{POF}_{3}$ and initiates an autocatalytic decomposition of the electrolyte. ${ }^{11}$ The resulting HF has been confirmed as discussed above. Interestingly, the GC-MS spectrum of the 4TB-containing electrolyte after storage has less changed compared to its fresh one, confirming that the thermal stability of the STD electrolyte has been improved by applying 4-TB.

The resulting HF from the thermal decomposition of electrolyte might deteriorate the cyclability of $\mathrm{LiMn}_{2} \mathrm{O}_{4}$. Fig. $6 \mathrm{~d}$ presents the cycle performance of $\mathrm{LiMn}_{2} \mathrm{O}_{4}$ electrode in the electrolyte with and without additive after storage at $55{ }^{\circ} \mathrm{C}$ for $72 \mathrm{~h}$, the data in which are the representative ones of five samples for each electrode (Fig. S2 $\dagger$ ). The cycling tests were performed in $\mathrm{Li} / \mathrm{LiMn}_{2} \mathrm{O}_{4}$ coin cells under $25{ }^{\circ} \mathrm{C}$ at $0.5 \mathrm{C}$ for the initial three formation cycles and at $1 \mathrm{C}$ for the remaining cycles. As shown in Fig. 6d, $\mathrm{LiMn}_{2} \mathrm{O}_{4}$ experiences fast capacity decay in the STD electrolyte after storage, showing a capacity retention of only $44 \%$ after 200 cycles compared to the $76 \%$ of that in the electrolyte containing 4-TB. Comparatively, the cycle performance of $\mathrm{LiMn}_{2} \mathrm{O}_{4}$ in the electrolytes before storage (Fig. 6e), which was obtained under the same cycling conditions as Fig. 6d, shows less difference between the STD electrolyte and the 4 -TB-containing one. The capacity retention of $\mathrm{LiMn}_{2} \mathrm{O}_{4}$ is $90 \%$ and $86 \%$ after 200 cycles, and $83 \%$ and $75 \%$ after 550 cycles, for the electrolytes with and without 4-TB, respectively. These analyses indicate that the electrolyte after thermal decomposition deteriorates the cyclability of $\mathrm{LiMn}_{2} \mathrm{O}_{4}$. It should be noted that there still exists a difference in cyclability of $\mathrm{LiMn}_{2} \mathrm{O}_{4}$ between the electrolytes with and without 4-TB under room temperature (Fig. 6e), which emphasizes the contribution of interphase film formed from 4-TB to the cyclability improvement of $\mathrm{LiMn}_{2} \mathrm{O}_{4}$. Therefore, the improved cyclability of $\mathrm{LiMn}_{2} \mathrm{O}_{4}$ comes from dual contributions of 4-TB: one is forming a protective interphase film from the preferential electrochemical-oxidation of 4-TB; the other is stabilizing the electrolyte by 4 -TB. The latter contribution has never been reported before, and therefore, 4-TB provides a more effective solution to the cyclability issue of $\mathrm{LiMn}_{2} \mathrm{O}_{4}$ under elevated temperature than those additives that have been reported before.

Since the thermal instability of the electrolyte results from trace protonic impurities, the improved thermal stability of the electrolyte should be related to the interaction of 4-TB with these protonic impurities. To confirm this interaction, $\mathrm{H}_{2} \mathrm{O}$ was added into DEC with and without 4-TB and the resulting mixtures were analyzed with GC-MS. The obtained results are presented in Fig. 7. Pure DEC shows its characteristic peak at $16.6 \mathrm{~min}$, as shown in Fig. 7a. When $1 \mathrm{wt} \%$ deionized water is added into pure DEC, no significant change in GC-MS spectrum is observed (Fig. 6b), suggesting that there is no interaction between DEC and $\mathrm{H}_{2} \mathrm{O}$. When $0.5 \mathrm{wt} \%$ 4-TB is added into pure DEC, the characteristic peak of 4-TB appears at $13.4 \mathrm{~min}$, as shown in Fig. 7c. No other peak appears in Fig. 7c, suggesting that there is no interaction between 4-TB and DEC. When $0.5 \mathrm{wt} \%$ 4-TB is added into the DEC containing $1 \mathrm{wt} \%$ deionized water, however, there appears a new peak at 14.3 min except for the characteristic peaks of 4-TB and DEC, as shown in Fig. 7d. Apparently, there exists an interaction between 4-TB and $\mathrm{H}_{2} \mathrm{O}$, which are related to $-\mathrm{CN}$ group. The $-\mathrm{CN}$ combines proton forming $-\mathrm{CNH}^{+}$, which then combines $\mathrm{H}_{2} \mathrm{O}$ forming $-\mathrm{C}(\mathrm{NH})$ $\mathrm{OH}_{2}{ }^{+}$that is finally transformed into $-\mathrm{C}\left(\mathrm{NH}_{2}\right) \mathrm{O}$, as shown in Fig. 7e. ${ }^{14}$ The peak at $14.3 \mathrm{~min}$ in Fig. $7 \mathrm{~d}$ corresponds to the coordinate of 4-TB with $\mathrm{H}_{2} \mathrm{O}$.

With the dual functionalities of 4-TB, the dissolution of manganese from $\mathrm{LiMn}_{2} \mathrm{O}_{4}$ and aluminum from current collector will be inhibited to a great extent. To confirm these contributions, the $\mathrm{LiMn}_{2} \mathrm{O}_{4}$ and lithium electrodes, taken from 


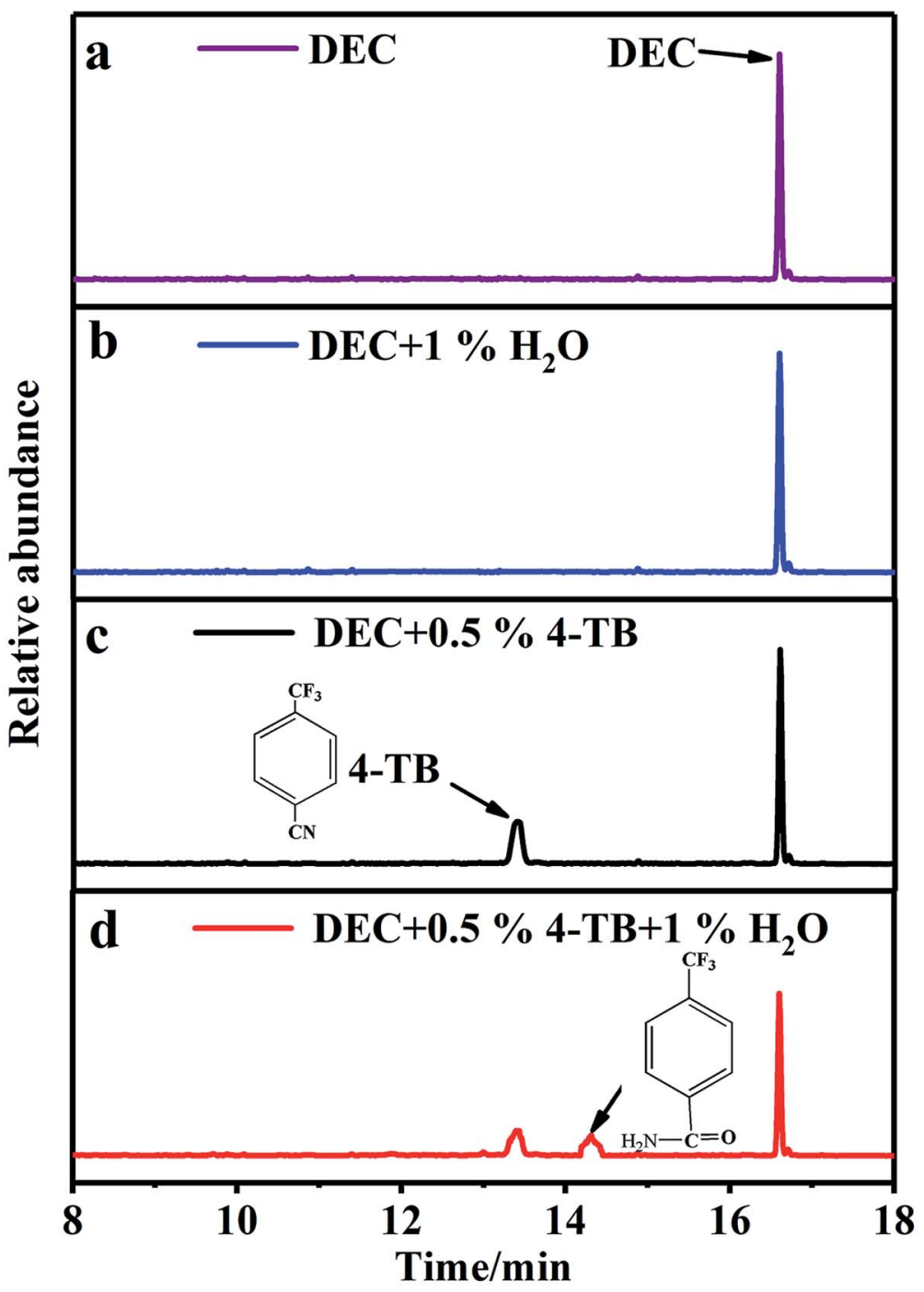

e<smiles></smiles><smiles>C=C[I+]</smiles><smiles>NC(=O)c1ccc(C(F)(F)F)cc1</smiles>

Fig. 7 GC-MS spectra of DEC containing $\mathrm{H}_{2} \mathrm{O}$ and/or 4-TB (a-d) and illustration on the coordination of 4-TB with $\mathrm{H}^{+}$and $\mathrm{H}_{2} \mathrm{O}$ (e).

the cells after cycling in Fig. 1a, were performed with morphological observations and element analyses. The obtained results are presented in Fig. 8. $\mathrm{LiMn}_{2} \mathrm{O}_{4}$ particles with spinel morphology and clean surface can be observed in the fresh electrode, as shown in Fig. 8a. After deep cycling in the electrolyte without additive under elevated temperature, however, $\mathrm{LiMn}_{2} \mathrm{O}_{4}$ particles have been covered by thick deposits (Fig. 8b), which mainly result from the electrochemical-oxidation decomposition of the electrolyte. During charge process, the solvents together with $\mathrm{PF}_{6}{ }^{-}$in the electrolyte will be electrochemical-oxidatively decomposed, forming deposits such as carbonates and $\mathrm{LiF}$, gases such as carbon oxide and acidic species such as HF. ${ }^{113}$ The deposits accumulate on $\mathrm{LiMn}_{2} \mathrm{O}_{4}$ as the cycling proceeds, accounting for the thick deposits observed in Fig. 8b. The resulting HF together with that from thermal decomposition of the electrolyte will cause the subsequent dissolution of manganese from $\mathrm{LiMn}_{2} \mathrm{O}_{4}$ and final structural collapse of $\mathrm{LiMn}_{2} \mathrm{O}_{4}$, as indicated by the arrow in Fig. 8b. Differently, the $\mathrm{LiMn}_{2} \mathrm{O}_{4}$ particle on the electrode cycled in the electrolyte containing 4-TB maintains the fresh morphology in Fig. 8a, as shown in Fig. 8c, confirming that a protective interphase film has been generated on $\mathrm{LiMn}_{2} \mathrm{O}_{4}$ 

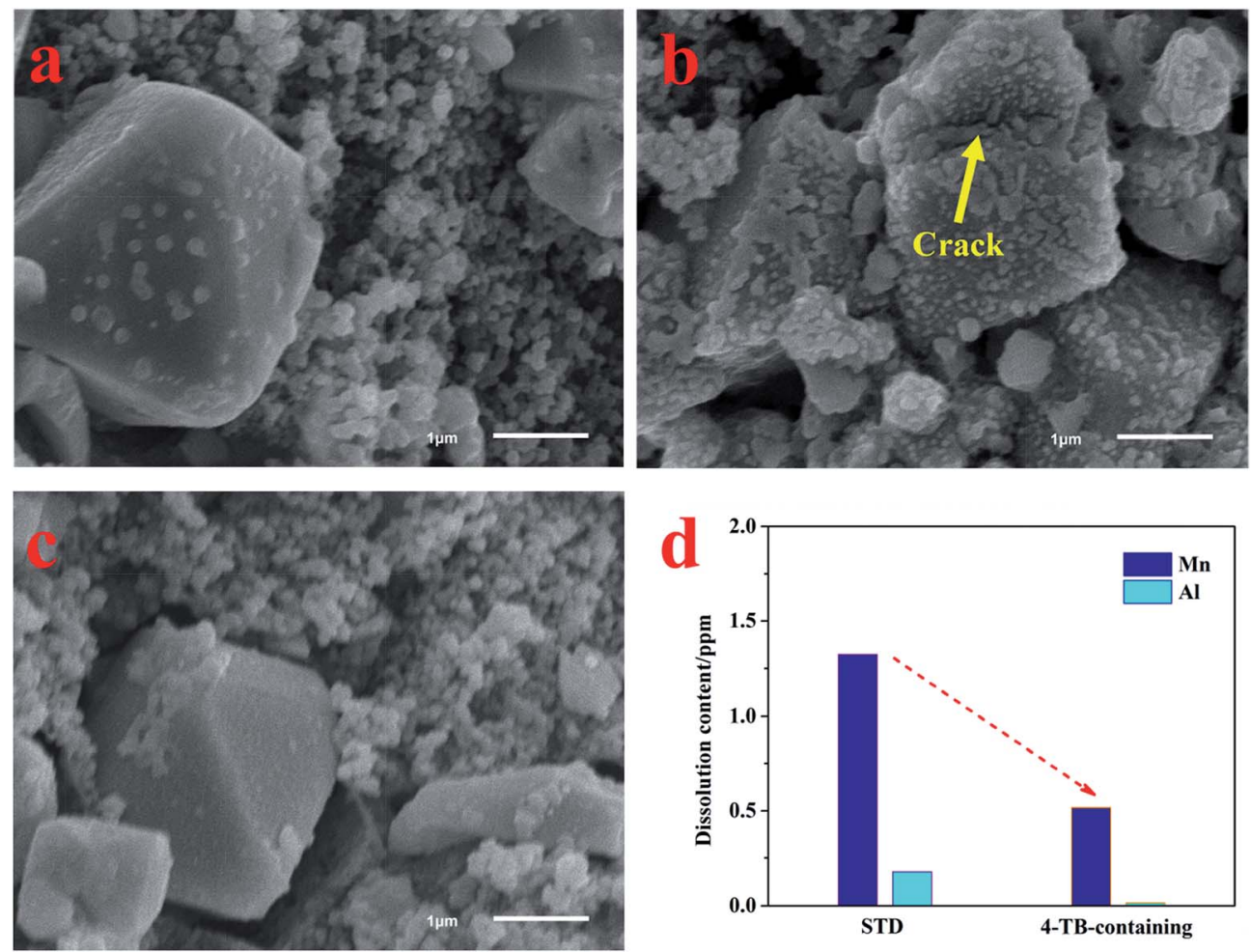

Fig. 8 SEM images of fresh $\mathrm{LiMn}_{2} \mathrm{O}_{4}$ electrode (a) and the cycled ones in STD (b) and 4-TB-containing (c) electrolytes. Contents of Mn and Al deposited on the cycled lithium electrodes (d). The cycled $\mathrm{LiMn}_{2} \mathrm{O}_{4}$ and lithium electrodes are taken from the cells after cycling test of Fig. $1 \mathrm{a}$.

from the preferential oxidation of 4-TB during initial cycling, which inhibits the electrolyte oxidation decomposition and the manganese dissolution. Fig. 8d presents the contents of manganese and aluminum deposited on lithium electrode of the cycled cells. The lithium electrodes were dissolved into $25 \mathrm{~mL}$ dilute nitric acid solution, which was then performed with ICP-AES analyses. As shown in Fig. 8d, besides manganese, aluminum can also be detected on the lithium electrode, suggesting that the $\mathrm{HF}$ also causes the corrosion of the current collector in $\mathrm{LiMn}_{2} \mathrm{O}_{4}$ electrode. The concentration of $\mathrm{Mn}$ and $\mathrm{Al}$

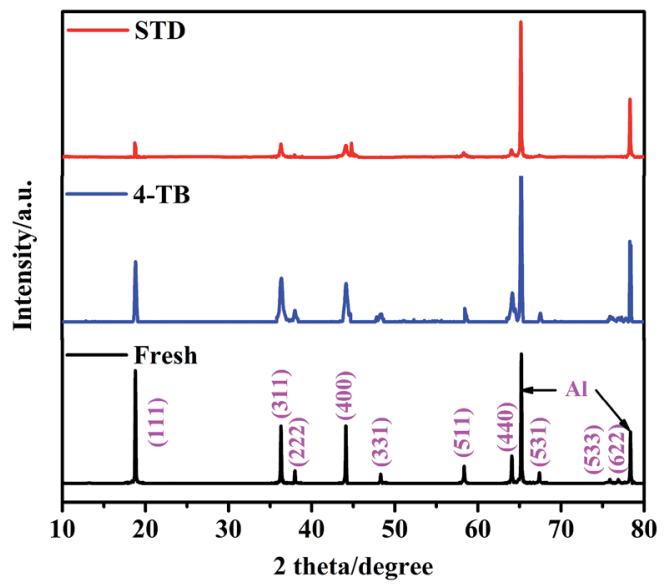

Fig. 9 XRD patterns of the cycled $\mathrm{LiMn}_{2} \mathrm{O}_{4}$ electrodes in STD and 4TB-containing electrolytes at $55^{\circ} \mathrm{C}$, with a comparison of fresh one. is $1.3 \mathrm{mg} \mathrm{L}^{-1}$ and $0.2 \mathrm{mg} \mathrm{L}^{-1}$ for the electrolyte without 4-TB but only $0.5 \mathrm{mg} \mathrm{L}^{-1}$ and $0.02 \mathrm{mg} \mathrm{L}^{-1}$ for the electrolyte with 4-TB, respectively. It is apparent that serious dissolutions of manganese and aluminum happen from $\operatorname{LiMn}_{2} \mathrm{O}_{4}$ electrode in the cycled cell using the electrolyte without additive, which can be inhibited significantly by applying 4-TB.

Fig. 9 shows XRD patterns of the cycled $\mathrm{LiMn}_{2} \mathrm{O}_{4}$ electrodes in STD and 4-TB-containing electrolytes at $55{ }^{\circ} \mathrm{C}$, with a comparison of fresh one. The diffractions of fresh electrode are characteristic of spinel $\mathrm{LiMn}_{2} \mathrm{O}_{4}$ structure together with the current collector aluminum. After 450 cycles at $55^{\circ} \mathrm{C}$ in the STD electrolyte, all the diffraction peaks for $\mathrm{LiMn}_{2} \mathrm{O}_{4}$ almost disappear, confirming that $\mathrm{LiMn}_{2} \mathrm{O}_{4}$ suffers structural deterioration. By contrast, the $\mathrm{LiMn}_{2} \mathrm{O}_{4}$ electrode cycled in 4-TB-containing electrolyte maintains the characteristic diffractions of spinel structure, confirming that the interphase film formed from 4-TB yields an effective protection for the structural integrity of $\mathrm{LiMn}_{2} \mathrm{O}_{4}$.

\section{Conclusions}

The cyclability of $\mathrm{LiMn}_{2} \mathrm{O}_{4}$ electrode under elevated temperature can be significantly improved by applying 4-TB as an electrolyte additive. This improvement is attributed to the dual functionalities of 4-TB. On the one hand, 4-TB can be oxidized electrochemically before the electrolyte oxidation decomposition, forming a protective interphase film on $\operatorname{LiMn}_{2} \mathrm{O}_{4}$. On the other hand, 4 -TB can coordinate with trace impurities such as 
small alcohol and water that are detrimental to the thermal stability of electrolyte. Therefore, the application of 4-TB can inhibit the formation of HF to a great extent by simultaneously inhibiting the electrochemical oxidation and thermal decompositions of electrolyte, and thus reduce the manganese dissolution from $\mathrm{LiMn}_{2} \mathrm{O}_{4}$ and aluminum from current collector, leading to the significantly improved cyclability of $\mathrm{LiMn}_{2} \mathrm{O}_{4}$.

\section{Conflicts of interest}

The authors declare that there is no conflict of interest.

\section{Acknowledgements}

This work is supported by the National Natural Science Foundation of China (Grant No. 21573080), the Natural Science Foundation of Guangdong Province (Grant No. 2014A030313424), the key project of Science and Technology in Guangdong Province (Grant No. 2016B010114001 and 2017A010106006), Guangzhou City Project for Cooperation among Industries, Universities and Institutes (Grant No. 201604016011).

\section{Notes and references}

1 Y.-M. Song, J.-G. Han, S. Park, K. T. Lee and N.-S. Choi, J. Mater. Chem. A, 2014, 2, 9506-9513.

2 A. Väyrynen and J. Salminen, J. Chem. Thermodyn., 2012, 46, 80-85.

3 G. H. Yang, J. L. Shi, C. Shen, S. W. Wang, L. Xia, H. S. Hu, H. Luo, Y. G. Xia and Z. P. Liu, RSC Adv., 2017, 7, 2605226059.

4 J. B. Goodenough, Solid State Ionics, 1994, 69, 184-198.

5 I. Scivetti and G. Teobaldi, J. Phys. Chem. C, 2015, 119, 2135821368.

6 L. Yang, M. Takahashi and B. Wang, Electrochim. Acta, 2006, 51, 3228-3234.

7 N.-S. Choi, J.-G. Han and S. Y. Ha, RSC Adv., 2015, 5, 27322748.

8 D. C. Tang, Y. Sun, Z. Z. Yang, L. B. Ben, L. Gu and X. J. Huang, Chem. Mater., 2014, 26, 3535-3543.

9 M. S. Whittingham, Chem. Rev., 2004, 104, 4271-4302.

10 J. C. Hunter, J. Solid State Chem., 1981, 39, 142-147.

11 X. Sun, H. S. Lee, X. Q. Yang and J. Mcbreen, Electrochem. Solid-State Lett., 2002, 5, A248-A251.

12 X. L. Liao, P. Y. Sun, M. Q. Xu, L. D. Xing, Y. H. Liao, L. P. Zhang, L. Yu, W. Z. Fan and W. S. Li, Appl. Energy, 2016, 175, 505-511.
13 L. D. Xing, W. S. Li, C. Y. Wang, F. L. Gu, M. Q. Xu, C. L. Tan and J. Yi, J. Phys. Chem. B, 2009, 113, 16596-16602.

14 R. J. Chen, F. Liu, Y. Chen, Y. S. Ye, F. Wu and L. Li, J. Power Sources, 2016, 306, 70-77.

15 G. J. Xu, Z. H. Liu, C. J. Zhang, G. L. Cui and L. Q. Chen, J. Mater. Chem. A, 2015, 3, 4092-4123.

16 C. Zhan, J. Lu, A. J. Kropf, T. P. Wu, A. Jansen, Y.-K. Sun, X. P. Qiu and K. Amine, Nat. Commun., 2013, 4, 1-8.

17 C. L. Tan, H. J. Zhou, X. H. Hou, D. S. Lu, M. Q. Xu and Q. M. Huang, J. Power Sources, 2008, 184, 408-413.

18 L. Sunhhye and C. Jaephil, Chem. Commun., 2008, 37, 44724474.

19 W. W. Sun, H. Q. Liu, Y. M. Liu, G. X. Bai, W. Liu, S. S. Guo and X. Z. Zhao, Nanoscale, 2015, 7, 13173-13180.

20 H. B. Lin, J. N. Hu, H. B. Rong, Y. M. Zhang, S. W. Mai, L. D. Xing, M. Q. Xu, X. P. Li and W. S. Li, J. Mater. Chem. A, 2014, 2, 9272-9279.

21 B. Li, Y. Q. Wang, H. B. Rong, Y. T. Wang, J. S. Liu, L. D. Xing, M. Q. Xu and W. S. Li, J. Mater. Chem. A, 2013, 1, 1295412961.

22 J. C. Burns, A. Kassam, N. N. Sinha, L. E. Downie, L. Solnickova, B. M. Way and J. R. Dahn, J. Electrochem. Soc., 2013, 160, A1451-A1456.

23 Y. M. Zhu, X. Y. Luo, M. Q. Xu, L. P. Zhang, L. Yu, W. Z. Fan and W. S. Li, J. Power Sources, 2016, 317, 65-73.

24 W. N. Huang, L. D. Xing, Y. T. Wang, M. Q. Xu, W. S. Li, F. C. Xie and S. G. Xia, J. Power Sources, 2014, 267, 560-565.

25 X. S. Wang, X. L. Liao, W. N. Huang, L. D. Xing, Y. H. Liao, Q. M. Huang, M. Q. Xu and W. S. Li, Electrochim. Acta, 2015, 184, 94-101.

26 W.-K. Shin, J.-H. Yoo and D.-W. Kim, J. Power Sources, 2012, 279, 737-744.

27 X. R. Yang, J. H. Li, L. D. Xing, Y. H. Liao, M. Q. Xu, Q. M. Huang and W. S. Li, Electrochim. Acta, 2017, 227, 2432.

28 F. Wu, M. Wang, Y. Su, S. Chen and B. Xu, J. Power Sources, 2009, 191, 628-632.

29 J. Q. Liu, Q. C. Zhuang, Y. L. Shi, X. D. Yan, X. Zhao and X. B. Chen, RSC Adv., 2016, 6, 42885-42891.

30 Y. Kusachi, Z. C. Zhang, J. Dong and K. Amine, J. Phys. Chem. C, 2011, 115, 24013-24020.

31 S. W. Mai, M. Q. Xu, X. L. Liao, L. D. Xing and W. S. Li, J. Power Sources, 2015, 273, 816-822.

32 M. Q. Xu, L. Zhou, Y. N. Dong, Y. J. Chen, J. Demeaux, A. D. Maclntosh, A. Garsuch and B. L. Lucht, Energy Environ. Sci., 2016, 9, 1308-1319. 